\title{
Registro y parametrización antropométrica del patrimonio arquitectónico: el Corral del Carbón de Granada
}

\author{
Recording and Anthropometric Parameterization of the Architectural \\ Heritage: Corral de Carbon, Granada
}

$\underline{\text { F.J. Roldán Medina }}^{(*)}$, J.F. Reinoso Gordo ${ }^{(* *)}$, A.J. Gómez-Blanco Pontes ${ }^{(* *)}$

\section{RESUMEN}

Se registra la geometría del edificio medieval del Corral del Carbón de Granada para posteriormente proceder al análisis metrológico y parametrización de sus dimensiones. El levantamiento se ha realizado mediante escáner láser 3D complementado con modelos fotogramétricos. Se adopta la premisa metrológica de que toda medida se compone con lados y diagonales de cuadrado antropométrico, lo que permite reconstruir las aparentes trazas del edificio. Se trata de una cuadrícula casi regular con el módulo de métrica Nazarí 2 de $182 \mathrm{~cm}$ como patrón cuadrado repetitivo, pero que adopta composiciones dinámicas en distintos elementos. Sorprende la curvatura de las galerías, y se detectan partes añadidas con distinta métrica. Los resultados animan a implantar los estudios antropométricos del patrimonio como fase de investigación histórica inmediatamente posterior al registro de su geometría, y previa a la modelización eBIM.

Palabras clave: Metrología, levantamiento, escáner-láser, fotogrametría, hispano-musulmán, arqueología.

\section{ABSTRACT}

The purpose of this work is to record the geometry of the medieval building of The Corral del Carbon, of Granada and then proceed to metrological and parameterization analysis of its dimensions. The survey was carried out using a $3 D$ laser scanner complemented with photogrammetric models. The metrological premise is adapted so that any measure is composed with sides and diagonals of anthropometric square, which allows for reconstruction of traces of the building. In this case it is an almost regular grid design with the $182 \mathrm{~cm}$ Nazarí-2 metric Module as a repetitive square pattern, and which also adopts dynamic compositions in different representative elements. The curvature of the galleries is surprising, and also detected, were parts that had been added with different metrics. The results encourage the implementation of the anthropometric heritage studies, as a historical research phase, immediately after the recording of its geometry, and prior to eBIM modeling.

Keywords: Metrology, survey, laser scanner, photogrammetry, Hispanic-Muslim, archeology.

(*) Doctor Arquitecto. Investigador. Laboratorio de Arqueología y Arquitectura de la Ciudad (LAAC), Granada (España). $(* *)$ Doctor en Ingeniería Cartográfica, Geodésica y Fotogrametría. Profesor titular (SMlab), Universidad de Granada (España). $(* * *)$ Doctor Arquitecto. Profesor titular (SMlab), Universidad de Granada (España).

Persona de contacto/Corresponding author: froldan@ugr.es (F.J. Roldán Medina).

ORCID: https://orcid.org/oooo-0002-2158-4936 (F.J. Roldán Medina); https://orcid.org/oooo-00o3-3808-1857

(J.F. Reinoso Gordo); https://orcid.org/oooo-0002-8415-110X (A.J. Gómez-Blanco Pontes).

Cómo citar este artículo/Citation: Roldán Medina, F.J.; Reinoso Gordo, J.F.; Gómez-Blanco Pontes, A.J. (2020). Registro y parametrización antropométrica del patrimonio arquitectónico: el Corral del Carbón de Granada. Informes de la Construcción, 72 (558): e337. https://doi.org/10.3989/ic.7200o

Copyright: (C) 2020 CSIC. Este es un artículo de acceso abierto distribuido bajo los términos de la licencia de uso y distribución Creative Commons Reconocimiento 4.o Internacional (CC BY 4.0). 


\section{INTRODUCCIÓN}

La necesidad de representación gráfica del patrimonio arquitectónico para su correcto registro científico (1) ha planteado históricamente varios inconvenientes técnicos, tanto gráficos como metrológicos, que poco a poco se van superando.

La sistematización de la Geometría Descriptiva por Gaspard Monge (2) en el siglo XVIII permitió la representación científica de las formas tridimensionales a partir de varias proyecciones diédricas (plantas, alzados y secciones). Poco después se adoptó el Metro como unidad básica del Sistema Internacional, lo que supuso la estandarización universal de las medidas permitiendo su precisa y operativa notación métrico decimal, así como el abandono del milenario sistema de unidades antropométricas (3).

No obstante el levantamiento arquitectónico mediante técnicas tradicionales siguió planteando enormes dificultades para la correcta toma de medidas, sobre todo de alturas, detalles complejos, descuadres y deformaciones. La acumulación de errores de lectura se multiplican en el necesario proceso de escalado y simplificación de la representación gráfica, por lo que las planimetrías así generadas presentan poco detalle y significativas desviaciones respecto de las medidas y proporciones reales (Figura 1).

El dudoso rigor métrico de los levantamientos analógicos está siendo subsanado con el reciente desarrollo de las técnicas digitales del escáner láser 3d y la fotogrametría, que permiten cada vez con mayor precisión y exactitud registrar la geometría más compleja (Figura 2).

Liberados de la incertidumbre de la medida de la arquitectura histórica que ha proporcionado su representación gráfica tradicional, es posible enfrentarse ahora con el rigor científi-

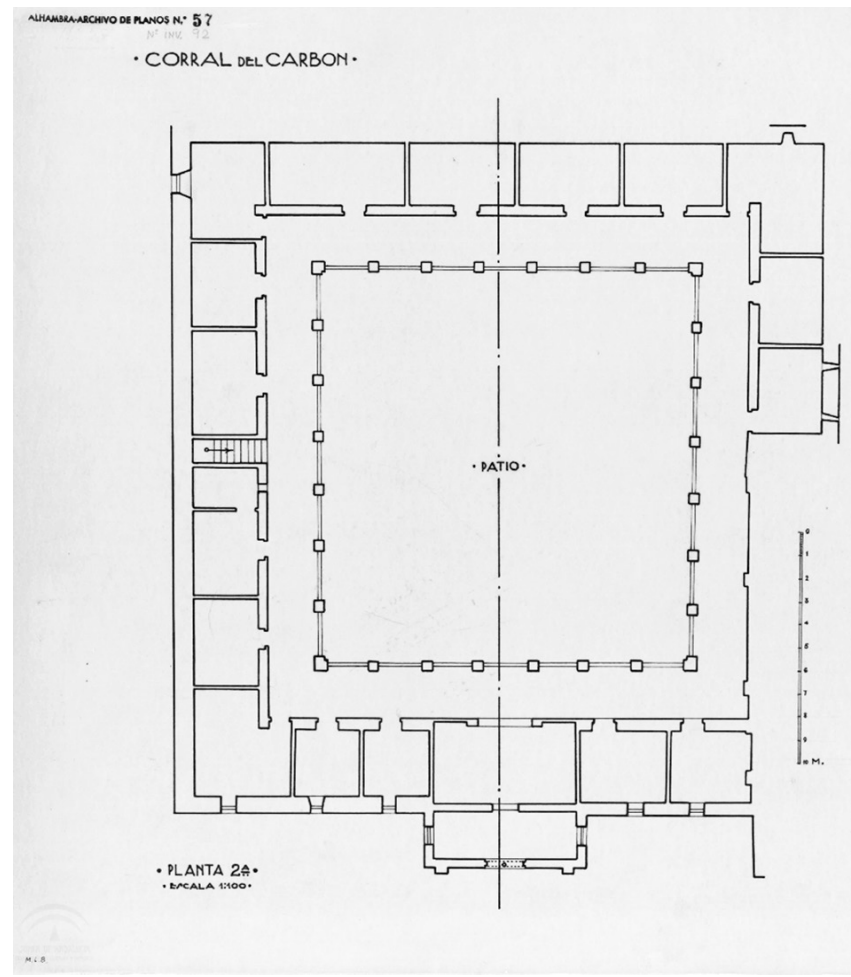

Figura 1. Corral del Carbón. Planta $2^{\mathrm{a}}$. López Bueno, M. Torres Balbás,L. (1929-1930). Archivo de planos de Alhambra nº 57. co necesario (4) al último y soslayado (5) problema del estudio de los sistemas de proporciones utilizados a lo largo de la historia en las formas arquitectónicas.

Desde el Renacimiento se vienen planteando esquemas lógicos y leyes para expresar numéricamente las proporciones de las construcciones del pasado (6). El hombre moderno ha intentado de muy diversas formas justificar los tamaños que presentan el todo y las partes de la arquitectura clásica (7). La cuestión de la necesaria conmensuración de la obra y la cuantificación de sus medidas (8) ha sido respondida con muy variadas propuestas, aunque hasta ahora no ha podido ser explicada con exactitud (9).

A nadie escapa que nuestra capacidad para interpretar con acierto estas obras depende de la aptitud para entender cómo fueron diseñadas y construidas, lo que significa conocer exactamente las reglas métricas que se utilizaron. Ahora que las nuevas herramientas digitales nos dan la capacidad para conocer con más exactitud lo que miden según nuestro actual esquema métrico decimal, existen las condiciones para estudiar objetivamente sus verdaderas proporciones y proponer esquemas metrológicos alternativos.

Bajo estas nuevas circunstancias se hizo el estudio modular de un significativo edificio de la época medieval en Granada, el Cuarto Real de Santo Domingo del siglo XIII, que ha permitido concluir que todas sus dimensiones se justifican mediante la adición de lados y diagonales de un mismo cuadrado (10). Los distintos tamaños resultan fracciones duodecimales de un módulo concreto, de acuerdo con el antiguo sistema de unidades antropométricas. Así se pudo acotar la totalidad de elementos del edificio mediante un patrón métrico cuadrado, o su mitad la escuadra, que se dispone recto o girado $45^{\circ}$. La expresión numé-

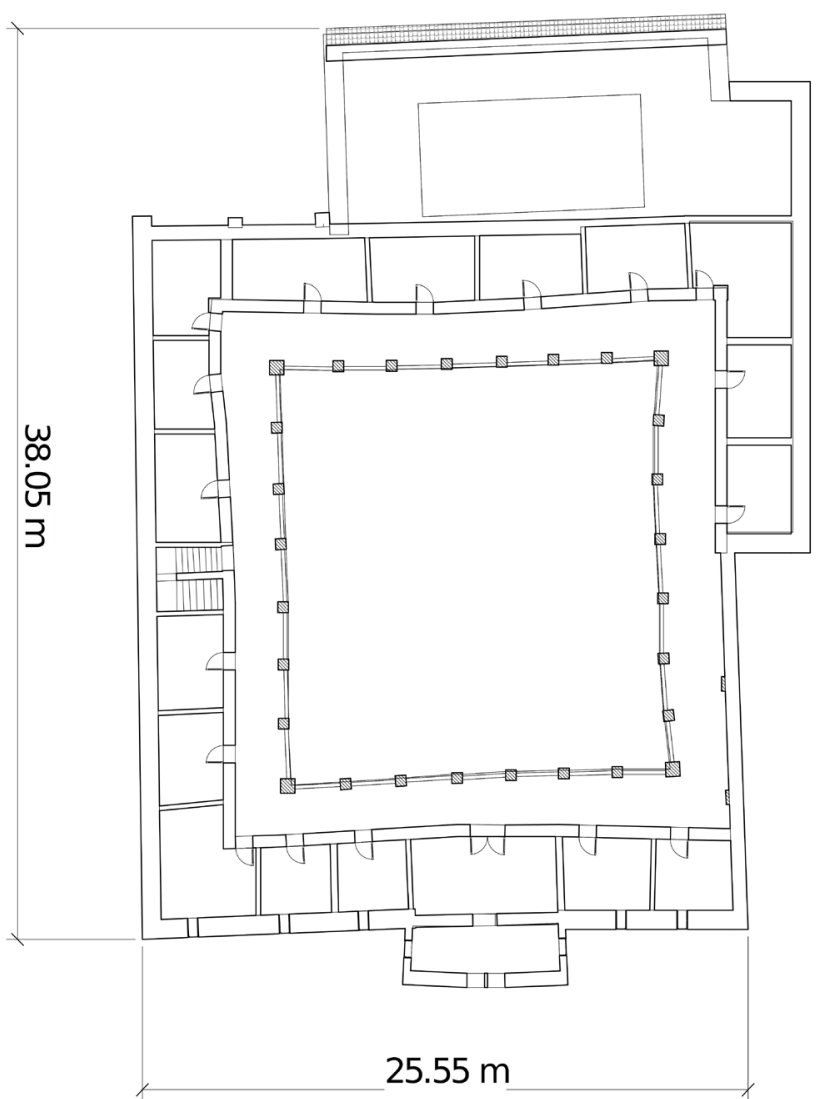

Figura 2. Planimetría de la segunda planta del Corral del Carbón obtenida de la nube de puntos del edificio completo. 
rica de las dimensiones se realizó mediante binomios de números enteros bajos (11). También se construyeron patrones métricos de doble graduación para la lectura directa de medidas.

Sorprendentemente, en el estudio de numerosas y variadas obras del pasado se ha observado la aplicación aparentemente universal de esta simple e inédita ley geométrica para la composición armónica de la arquitectura. Ello ha animado a desarrollar la metodología de los estudios antropométricos del patrimonio aquí utilizada, que identifica las trazas compositivas y las unidades exactas de medida teórica con que pudieron construirse las obras y sus partes (12).

Los resultados obtenidos hasta ahora en Granada han permitido esbozar sus últimos periodos métricos (13). Además de la medida Castellana de la vara de Burgos con que se edificó la mayor parte del casco histórico de Granada en la Edad Moderna, destaca en la construcción del Palacio de Carlos V y en otras obras de esta ciudad atribuibles a su reinado la utilización de una referencia distinta que suponemos corresponde con la antigua vara de Toledo. Por su parte el Palacio de Comares, el Patio de los Leones, y buena parte de la Granada nazarí, fueron construidos con una métrica de $182 \mathrm{~cm}$. Sin embargo las obras más antiguas de este reinado (Cuarto Real, Palacio del Partal, Generalife,...) presentan distinto módulo, uno mayor de $208 \mathrm{~cm}$.

Se acomete en esta ocasión el levantamiento y el estudio antropométrico del edificio del Corral de Carbón, única alhóndiga árabe conservada en España. Fue construida en la primera mitad del siglo XIV en el centro de Granada, próxima a la mezquita mayor, la Alcaicería y el Zacatín, siguiendo el modelo de patio con galerías a las que se abrían las habitaciones en que se dividen las cuatro naves que lo rodean. La planta baja se destinaba a almacenes y cuadras; las altas a alojamiento. Por su tamaño, monumentalidad y riqueza decorativa, sobre todo de su portada, este fundaq granadino sería excepcional ya en su época (14).

\section{METODOLOGÍA}

Para el presente estudio se han utilizado y generado como fuentes de investigación una serie de recursos geométricos. En primer lugar está el propio edificio objeto de análisis, del que se ha obtenido la planimetría general realizada mediante tecnología escáner láser 3D (15). Con una serie de instantáneas se ha generado un modelo fotogramétrico de la portada y otro de detalle de su mocárabe. Posteriormente la superposición de las fuentes gráficas generadas ha sido analizada con precisión digital bajo la premisa de composición modular antropométrica a base de lados y diagonales de cuadrado.

\subsection{El levantamiento}

El material utilizado por el Laboratorio para el Levantamiento y Modelización del Patrimonio Arquitectónico (SMlab) en el levantamiento del edificio fue un escáner laser BLK36o y una estación total TSo2, ambos de la marca Leica. La exactitud del escáner es de $6 \mathrm{~mm}$ a $10 \mathrm{~m}$ de distancia y de $8 \mathrm{~mm}$ a $20 \mathrm{~m}$ según las especificaciones del fabricante de 1 sigma ( $1 \sigma)$. La exactitud de la estación total es de 3 “ en ángulos y $1.5 \mathrm{~mm} \pm 2$ ppm en medición de distancias.

El levantamiento general del Corral del Carbón constó de 99 escaneos, algunos de ellos se muestran mediante esferas grises en la Figura 3. Las esferas están colocadas en la verdadera posición en la que fueron tomados los escaneos. Se puede ver la distribución de varios de los escaneos, algunos camuflados entre la nube de puntos.

El escáner BLK36o no tiene nivel, de forma que se ha utilizado la estación total para conseguir la nivelación y referenciación del edificio. Se dieron coordenadas a un grupo de dianas distribuidas por todo el patio interior del Corral del Carbón que sirvieron como referencias para realizar el ajuste. El proceso de escaneo proporcionó la estructura global del edificio (pilares, muros, plantas, techos y cubierta) y cuando se necesitó una textura más detallada se recurrió a una toma de fotografías para calcular su estructura fotogramétrica (SfM) como en el caso de la puerta de entrada.

La calidad de cada escaneo referida a la densidad de puntos se puede seleccionar de entre tres niveles: baja (un punto cada 20 $\mathrm{mm}$ ), media (un punto cada $10 \mathrm{~mm}$ ) y alta (un punto cada 5 $\mathrm{mm}$ ). En nuestro caso se usó la calidad media en la mayoría de los escaneos excepto en el caso de las habitaciones donde se utilizó una calidad baja, mientras que en la captura del mocárabe de la puerta de entrada se utilizó una calidad alta.

El proceso de registro consistió en poner cada uno de los escaneos en el mismo sistema de referencia, de tal forma que el resultado final es una nube de puntos que define el edificio com-

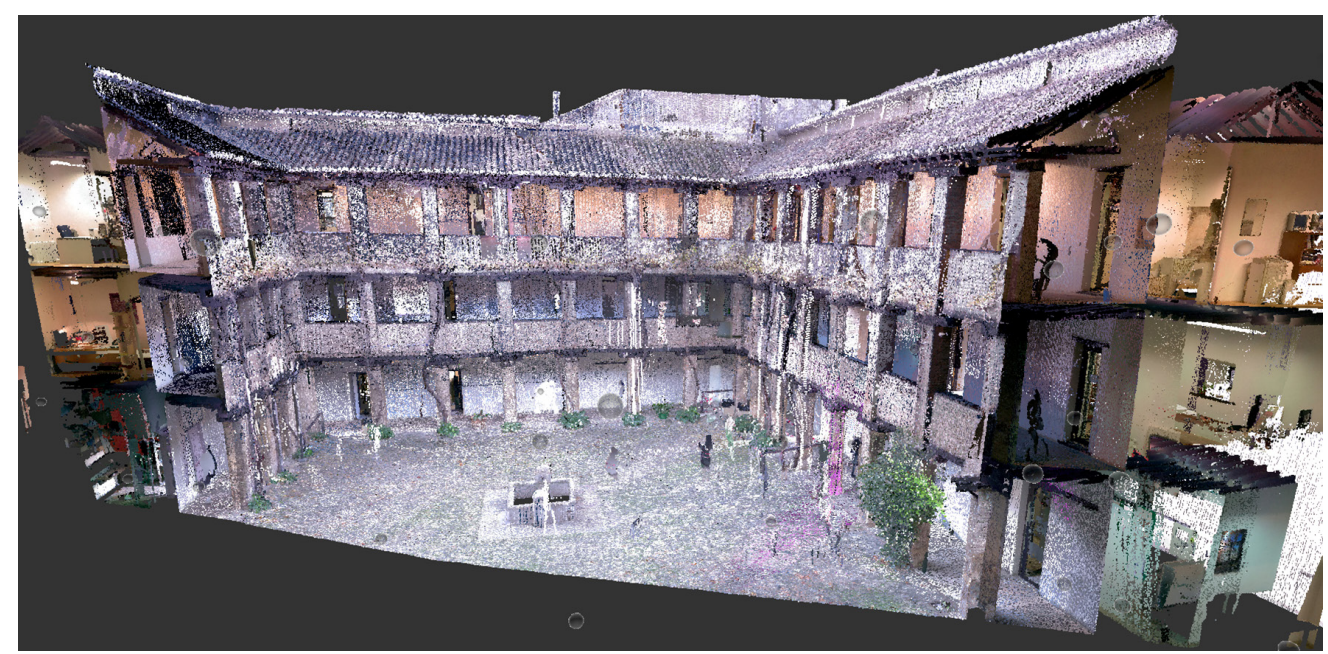

Figura 3. Perspectiva de una sección de la nube de puntos registrados junto a algunas de las posiciones del escáner (esferas grises). 
pleto. Existe la posibilidad de hacer el registro al mismo tiempo que se van realizando los escaneos sobre el terreno, aunque a veces es preferible realizarlo en gabinete mediante el software apropiado. En nuestro caso optamos por realizar el registro en gabinete ya que ahorra tiempo en la toma de datos dentro del edificio, cuyo acceso estaba limitado debido a la necesidad de no interferir demasiado con las visitas normales de los turistas.

El software que usamos para el registro de escaneos fue Recap Pro, que permite elaborar informes después del registro individual de cada escaneo. La información de calidad proporcionada por cada registro es: a) recubrimiento, que representa el porcentaje que cada escaneo que va a ser registrado (EAR) tiene en común con el escaneo que sirve de referencia y que ya estaba registrado previamente (ERP), b) el equilibrio es una medida referida a la contribución relativa de la nube de puntos en las tres direcciones ortogonales del espacio; indica si el registro del EAR ha sido influenciado de una forma homogénea por las tres direcciones ortogonales del espacio, c) points $<6 \mathrm{~mm}$ indica el porcentaje de puntos de EAR con una diferencia de posicionamiento menor de 6 mm respecto al ERP. La siguiente Tabla 1 muestra la calidad de los parámetros para una pequeña muestra de escaneos.

Tabla 1. Muestra de registro de escaneos que indica la calidad por medio de tres parámetros: recubrimiento, equilibro y points $<6 \mathrm{~mm}$.

\begin{tabular}{|l|c|c|c|}
\hline $\begin{array}{c}\text { Nombre } \\
\text { del escaneo }\end{array}$ & $\begin{array}{c}\text { Recubrimiento } \\
\text { (\%) }\end{array}$ & $\begin{array}{c}\text { Equilibro } \\
\text { (\%) }\end{array}$ & $\begin{array}{c}\text { Points } \\
<\mathbf{6 ~ m m}\end{array}$ \\
\hline Corral 4 & 24.7 & 87.5 & 94.6 \\
\hline Corral 5 & 33.5 & 63.5 & 99.6 \\
\hline Corral 6 & 31.2 & 50.0 & 98.6 \\
\hline Corral 7 & 20.1 & 20.3 & 99.7 \\
\hline
\end{tabular}

Por su parte la portada del edificio y su mocárabe fueron objeto de sendos registros fotogramétricos mediante una serie de instantáneas tomadas con una cámara Nikkon D5300 y procesadas por el programa Memento, ahora llamado Recap Photo. Otra serie de aplicaciones han sido usadas para la generación de ortofotos (MeshLab), el tratamiento de datos numéricos (Excel) y la edición de imágenes (Photoshop). Para su encaje y análisis vectorial se ha utilizado Autocad.

Para la verificación de resultados y la revisión de los documentos gráficos generados se han comprobado una serie de medidas con un distanciómetro Disto Plus Leica de $1.5 \mathrm{~mm}$ de precisión a $200 \mathrm{~m}$.

\subsection{El estudio antropométrico}

Sobre la planimetría general del láser 3D se ajusta la escala de las distintas ortofotos de detalle de los modelos fotogramétricos, constituyendo el conjunto gráfico la fuente de la investigación del trabajo de gabinete de los estudios antropométricos.

En la Antropometría o proceso de arquitectura inversa se adopta un tamaño de cuadrado que permita justificar la dimensión de los principales elementos de la obra mediante un número entero y bajo de lados y diagonales, comprobando que las dimensiones secundarias también se ajustan al cuadrado, o a sus divisiones duodecimales. La dimensión de la mayor modulación que se pueda reconstruir del edificio permite establecer con precisión el valor teórico del módulo antropométrico braza $\mathrm{M}$ utilizado en su construcción. En base a esa referencia se identifican y acotan las distintas tramas modulares $\sqrt{ } \mathbf{2}$ que definen las formas arquitec- tónicas, siempre superponiendo los resultados a la fuente de investigación para que las diferencias sean contrastables. Gráficamente se representa la braza o módulo $\mathrm{M}$ con un cuadrado, y sus fracciones antropométricas con escuadras proporcionales. Aquí se ha utilizado el tamaño codo $(\mathrm{M} / 4)$ dividido en 6 palmos, y el tamaño palmo (M/24) dividido en 4 dedos. Numéricamente los valores obtenidos son teóricos. Se trata de dimensiones nominales que no coincidirán exactamente con la medida real de la parte, debido a los errores de fabricación y al devenir del tiempo. Como en todo proceso productivo es necesario establecer una tolerancia para la aceptación del resultado. Aquí se ha adoptado el 1\% de desviación máxima sobre el valor nominal, tolerancia admisible en las tareas manuales de nueva construcción.

En el trabajo de campo de los estudios antropométricos la fuente de investigación es directa, pues se trata de construir con la métrica deducida patrones y reglas de doble graduación lado-diagonal para la lectura y confrontación de medidas in situ $(16,17,18)$.

\section{RESULTADOS Y DISCUSIÓN}

Como primer y fundamental objetivo se ha registrado la actual geometría del edificio, generándose una serie de modelos digitales y planimetrías de calidad que satisfacen la exactitud de medida que exige el método científico (19) de análisis metrológico, pues el error cometido en el levantamiento es muy inferior a la tolerancia considerada en la antropometría.

Las ortoimágenes mixtas generadas por escáner láser 3D y fotogrametría documentan las dimensiones generales de la edificación en planta baja y sección (Figura 4), la portada en alzado, plantas y secciones (Figura 5), así como las proyecciones paralelas del mocárabe (Figura 6).
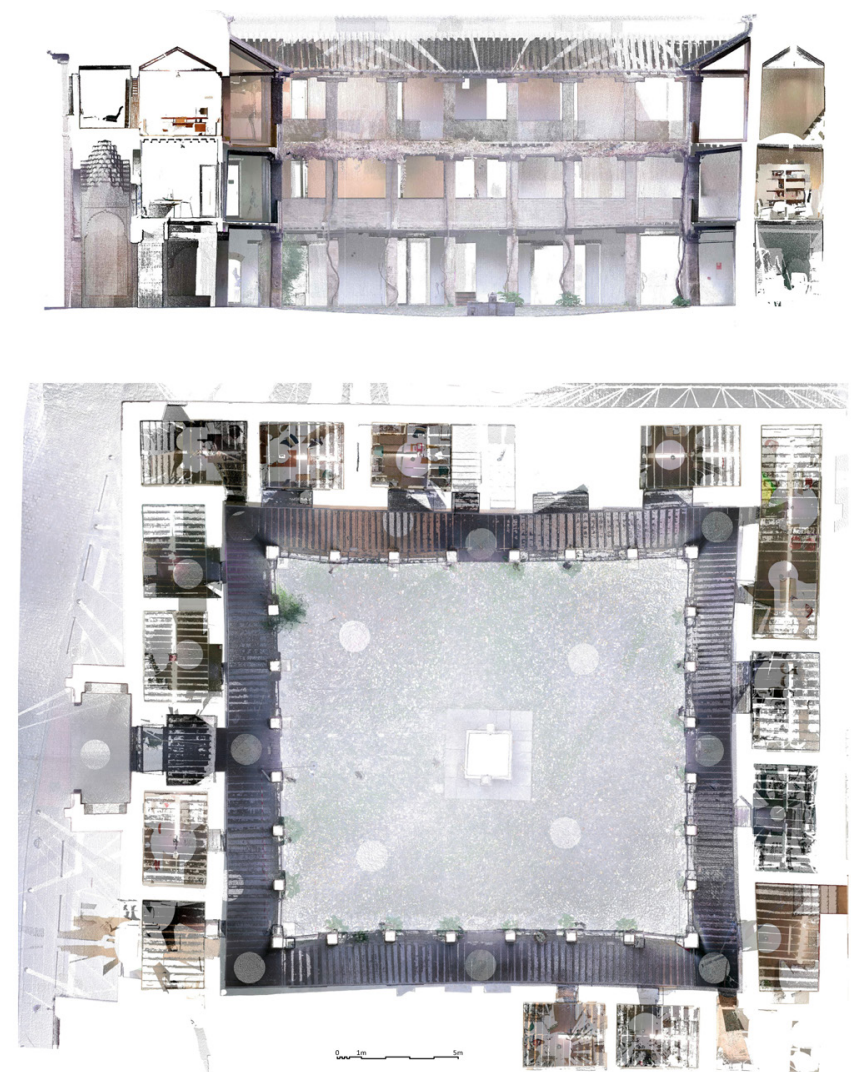

Figura 4. Sección y Planta baja de suelos y techos. Modelo escáner láser $3 \mathrm{D}$. 

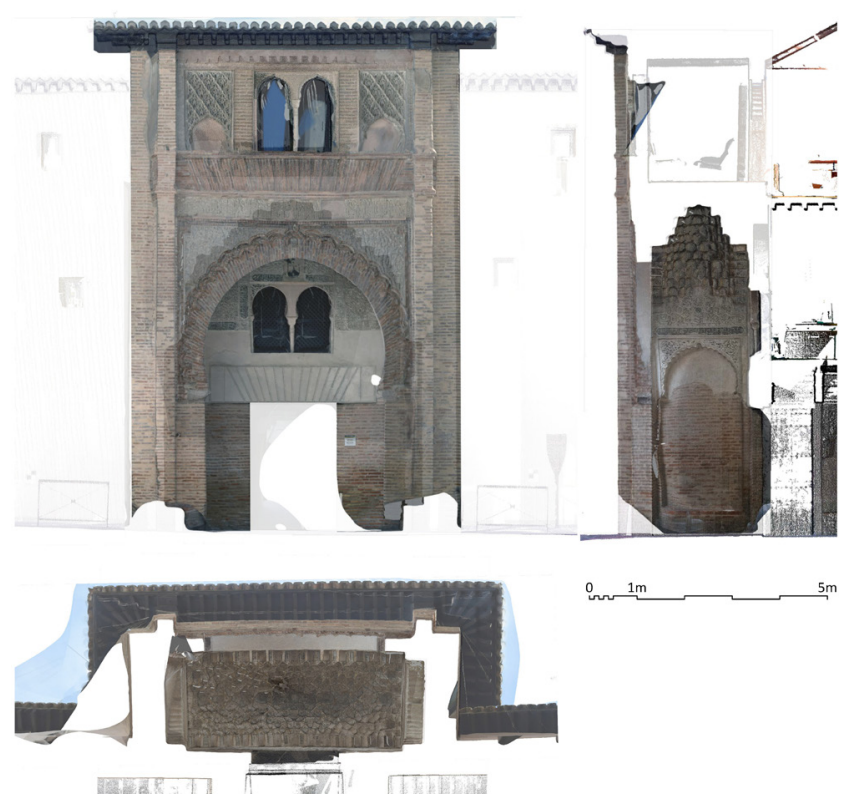

Figura 5. Alzado, planta cenital y sección de la portada. Modelo mixto.

\subsection{Las trazas}

La antropometría de la planta general del edificio (Figura 7) identifica una trama modular compositiva en base a un módulo M de $181.86 \mathrm{~cm}$, con el sistema de unidades de la Tabla 2. Coincide prácticamente con el valor obtenido en el estudio de la fachada del palacio de Comares de la Alhambra $(181.88 \mathrm{~cm})$ que sirvió de referencia para establecer la métrica Nazarí 2. Esta medida podría haber sido instaurada por Ismail I a partir de 1314 en sustitución de la Nazarí 1 de 208 cm.

El módulo braza de unos $182 \mathrm{~cm}$ queda identificado en primer lugar en el ancho del hueco de entrada al edificio, así como en el ámbito de tránsito hasta el patio a través del vestíbulo. Éste es el ancho teórico de las galerías y la distancia que mantienen de media las pilastras de las galerías de acceso y opuesta. Una cuarta parte de este valor -o codo de $45.5 \mathrm{~cm}$ - tiene de lado

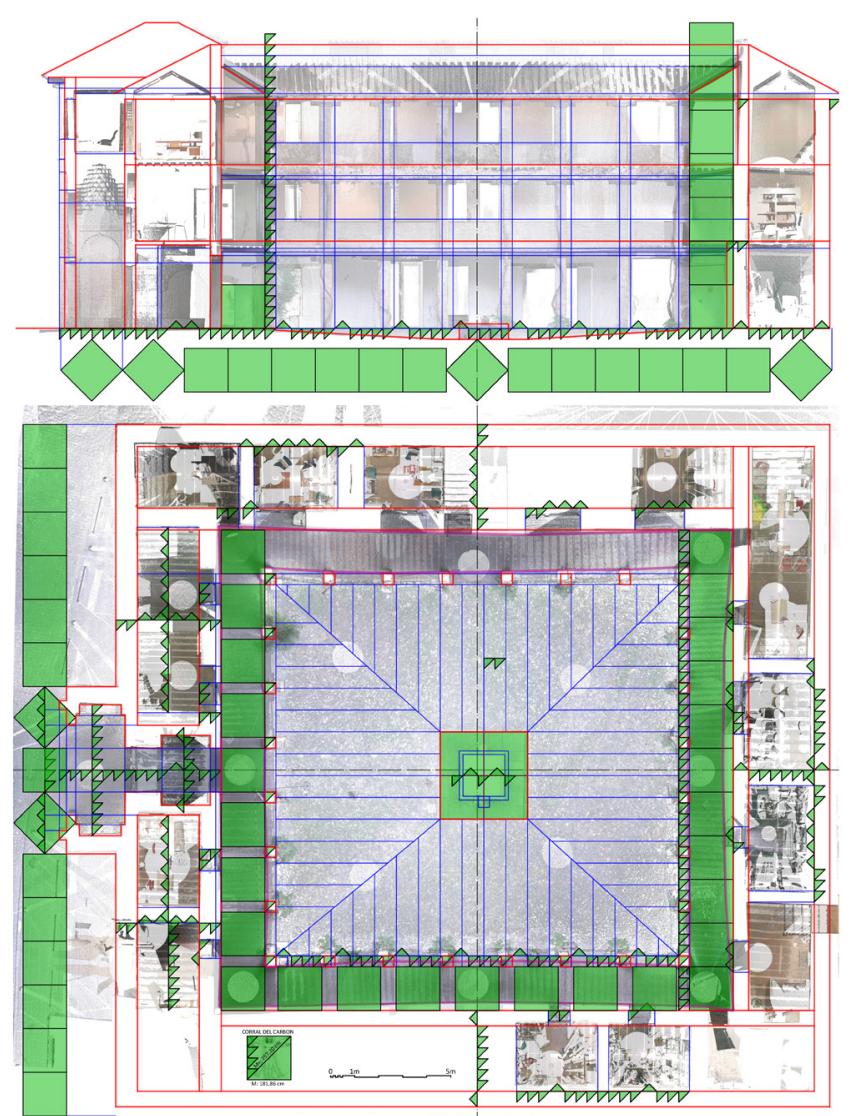

Figura 7. Antropometría de las trazas generales. Sección y Planta baja.

cada pilastra (Figura 8), por lo que el ancho total de patio incluidas las galerías alcanza las 11 brazas enteras (20 m). También se detecta que la plataforma enlosada de la fuente es un cuadrado de 2 brazas de lado, y que las líneas paralelas del empedrado del patio se separan regularmente 2 codos.

Como reiteradamente se ha observado en otras representativas obras históricas, las composiciones estáticas o en cuadrícula regular se combinan también con diagonales en el dise-
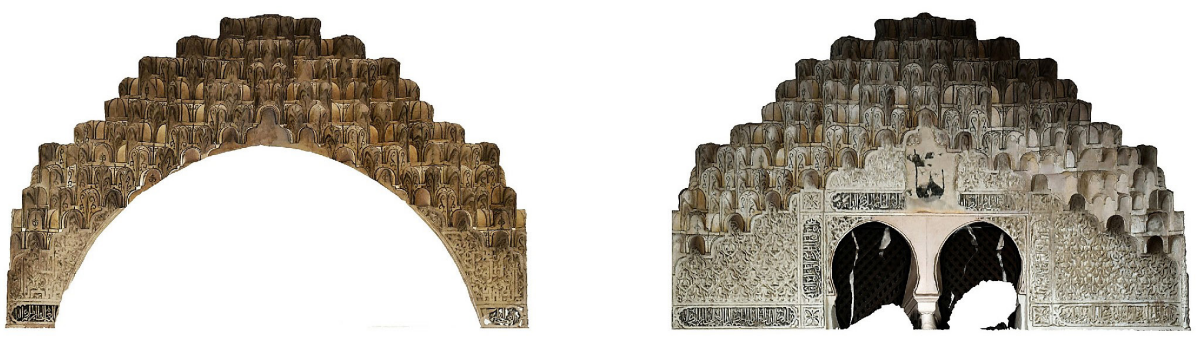

Alzado 1
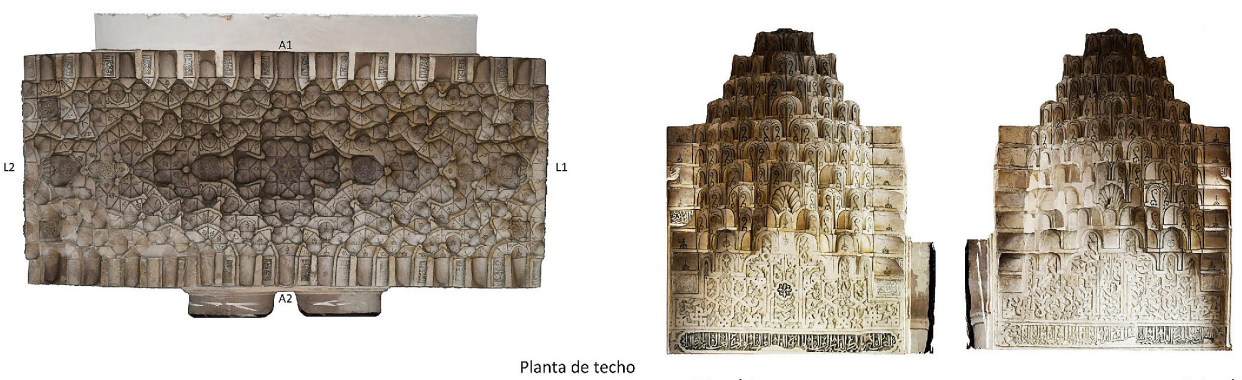

Figura 6. Alzados y planta cenital del mocárabe. Modelo fotogramétrico. 
Tabla 2. Unidades del sistema.

\begin{tabular}{|c|l|l|c|c|}
\hline FRACCIÓN & UNIDAD & UNIT & M (cm) & $\mathbf{M} \cdot \sqrt{ } \mathbf{2}(\mathbf{c m})$ \\
\hline $\mathbf{1}$ & BRAZA & FATHOM & 181,86 & 257,19 \\
\hline $\mathbf{1 / 2}$ & VARA & YARD & 90,93 & 128,59 \\
\hline $\mathbf{1 / 4}$ & CODO & CUBIT & 45,47 & 64,30 \\
\hline $\mathbf{1 / 6}$ & PIE & FOOT & 30,31 & 42,86 \\
\hline $\mathbf{1 / 8}$ & CUARTA & SPAN & 22,73 & 32,15 \\
\hline $\mathbf{1 / 2 4}$ & PALMO & PALM & 7,58 & 10,72 \\
\hline $\mathbf{1 / 9 6}$ & DEDO & DIGIT & 1,89 & 2,68 \\
\hline $\mathbf{1 / 3 8 4}$ & GRANO & & 0,47 & 0,67 \\
\hline
\end{tabular}

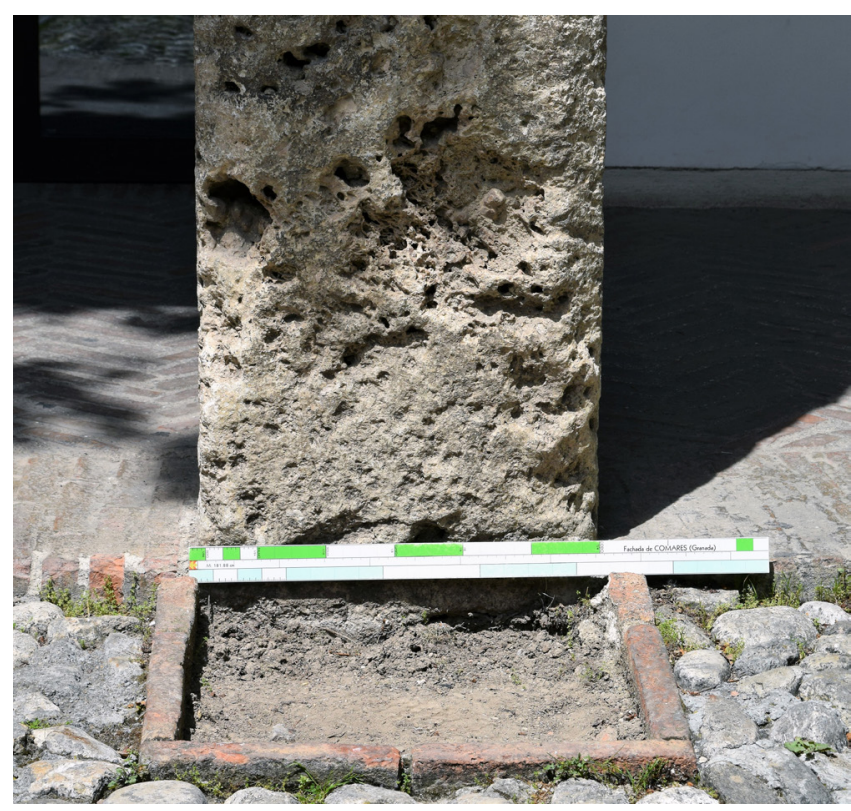

Figura 8. Pilastras de un codo de $45.5 \mathrm{~cm}$.

ño de las trazas generales de los edificios. Se trata por tanto de tramas dinámicas compuestas por cuadrados, rectángulos en proporción $\sqrt{ } 2$ y rectángulos de plata. Así la distancia de separación entre las pilastras de las galerías laterales del patio es algo mayor que en las galerías de entrada y fondo, ajustándose a una media de $\sqrt{ } 2+3$ codos, es decir, una diagonal y tres lados de codo cuadrado, que en esta métrica representan unos $2 \mathrm{~m}$. Por ello la planta rectangular del edificio no es cuadrada como aparenta, sino con un fondo algo mayor, que para el total del patio incluidas galerías sería de $7 \cdot \sqrt{ } 2+37$ codos o $21.32 \mathrm{~m}$.

Por su parte las crujías que rodean al patio presentan muros de 2 codos de espesor y ámbitos de $\sqrt{ } 2$ braza en las exteriores (acceso e izquierda), o muros de $\sqrt{ } 2$ codo de espesor y ámbitos de 6 codos en las crujías interiores. Con este esquema de patio cuasi cuadrado y 4 crujías el edificio alcanza un ancho total de $6 \cdot \sqrt{ } 2+54$ codos de ancho $(28.41 \mathrm{~m})$ por un fondo de $13 \cdot \sqrt{ } 2+47$ codos sin contar la portada $(29.73 \mathrm{~m})$.

Los niveles o alturas presentan valor racional en codos enteros. La cota del primer piso es 8 , la del segundo 15 , y la de aleros 21. La fuente se localiza a -1 .

La mayor parte de elementos de la planta general se ajusta en tamaño y posición a la trama dinámica teórica generada, con desviaciones inferiores al $1 \%$ que se ha adoptado como tole- rancia. Aunque como casi siempre ocurre, se presentan deformaciones e irregularidades mayores que pueden ser objeto de análisis puntual.

En este caso sorprende la excepcional curvatura que presentan las galerías y muros del patio, que en algunos casos supera los $40 \mathrm{~cm}$ sobre su alineación teórica. Se descartan causas patológicas que pudieran ocasionar estos desplazamientos de trazas, que evidentemente producen ciertos efectos visuales apenas perceptibles cuando se recorre el patio. Mientras que en el interior las galerías se curvan hacia fuera, en el exterior el patio parece más grande. Todo un recurso propio del arte del simulacro (20).

Existe un ligero desplazamiento paralelo de los ejes de la plataforma de la fuente y del empedrado del patio respecto de los ejes generales del edificio. Este mismo recurso se ha observado en otras obras andalusíes y clásicas, y está ligado generalmente con una reforma posterior a la fundación del edificio.

Por otra parte se detecta métrica Castellana en el ámbito de $1.25 \mathrm{~m}$ o 3 codos de la escalera con huellas de 1 pie $027.9 \mathrm{~cm}$, y en los restos de solería en la galería del fondo sur con ladrillos de 1 pie de largo y $\sqrt{ } 2+2$ dedos de grueso $(6 \mathrm{~cm})$.

Estos restos de solería de ladrillo han sido recientemente protegidos por presentar mal estado de conservación, y suponemos que son a los que se refiere Gómez Moreno cuando escribe que «Las galerías de planta baja tuvieron pavimento de ladrillos de canto, a juzgar por un trozo encontrado en la de sur» (21).

Frente a la constatación de la métrica Castellana de dicho trozo, el presente estudio también identifica el resto de solería de ladrillo de planta baja, mucho mejor conservada y posiblemente moderna, con la medida Nazarí 2 de las trazas del edificio. Así el encintado entre pilastras del patio tiene su ancho correspondiente de 1 codo, con ladrillos de 2 dedos de grueso, 2 palmos de ancho y casi 1 cuarta de largo. El diseño alterna filas de dos ladrillos de canto con otras de un canto y dos testas, que se repiten cada $\sqrt{ } 2$ palmo como muestra la Figura 9.

Este mismo formato de ladrillo presenta el pavimento en espiga de las galerías, con franjas de $\sqrt{ } \mathbf{2}$ cuarta de ancho nominal, y un ratio de cuatro gruesos cada cuarta $(22.7 \mathrm{~cm})$ que producen juntas de 1 dedo (Figura 10).

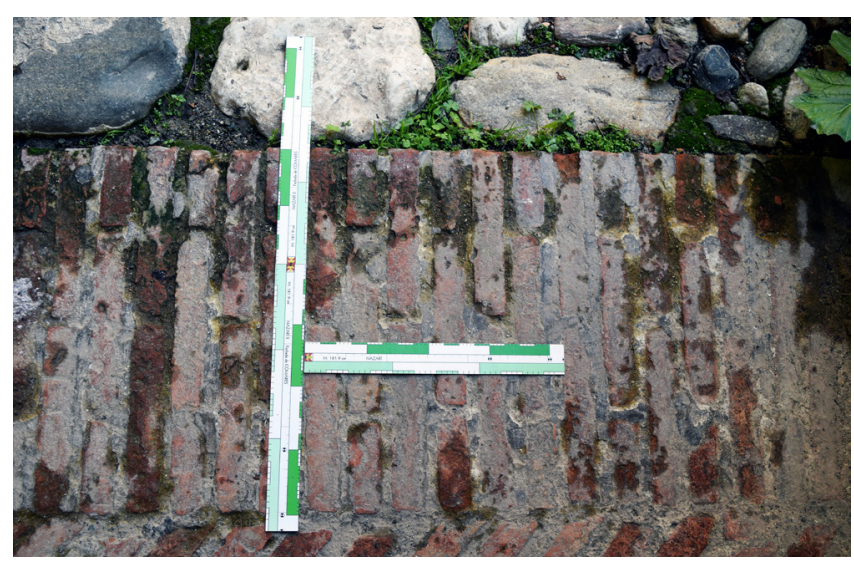

Figura 9. Encintado entre pilastras. 


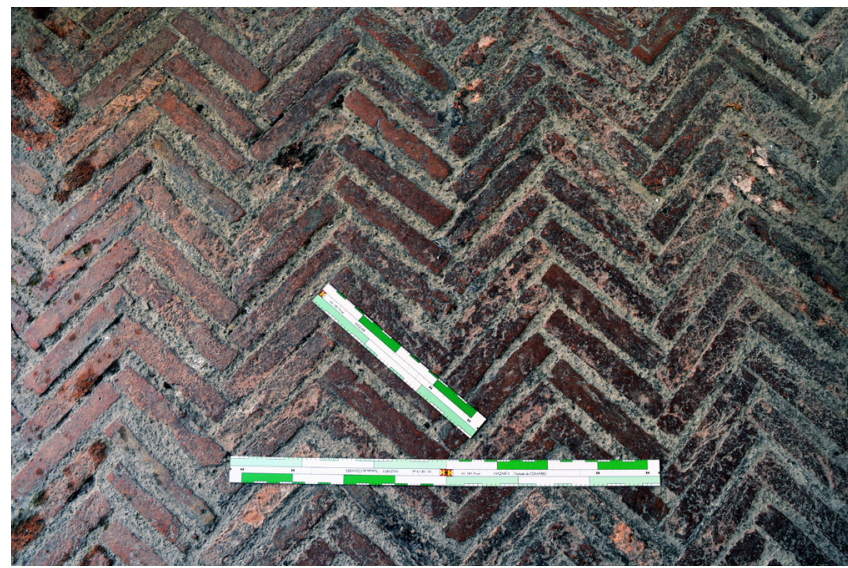

Figura 10. Solería en espiga.

Se constata que el largo teórico del ladrillo utilizado es de $4 \cdot \sqrt{ } 2+6$ dedos, lo que produce un formato de $22 \times 10.7 \times 3.8 \mathrm{~cm}$ que permite las juntas en ambos aparejos.

\subsection{La portada}

El cuerpo de portada (Figura 11) tiene un representativo ancho de $2 \cdot \sqrt{ } 2+1$ brazas, sus aleros se elevan hasta los 23 codos, y avanza 5 codos del plano de la fachada del edificio $(6.96 \times 10.45 \times 2.27 \mathrm{~m})$. El ancho del alfiz de $5 \cdot \sqrt{ } 2+4$, y el del arco de $3 \cdot \sqrt{ } 2+4$ codos, enmarcan la puerta adintelada de 4 codos de ancho por 6 de alto (Figura 12). Esta misma proporción 2:3 presenta la totalidad del alzado de la portada.

El ligero apuntado del arco se debe a dos centros desplazados 2 palmos del eje a una altura de $\sqrt{ } \mathbf{2}+48$ palmos. Las trazas de arco se prolongan en herradura hasta los 39 palmos de altura. El replanteo de la decoración angrelada se realiza con arquillos de 18 dedos de radio $(34.1 \mathrm{~cm})$ sobre arcos de replanteo
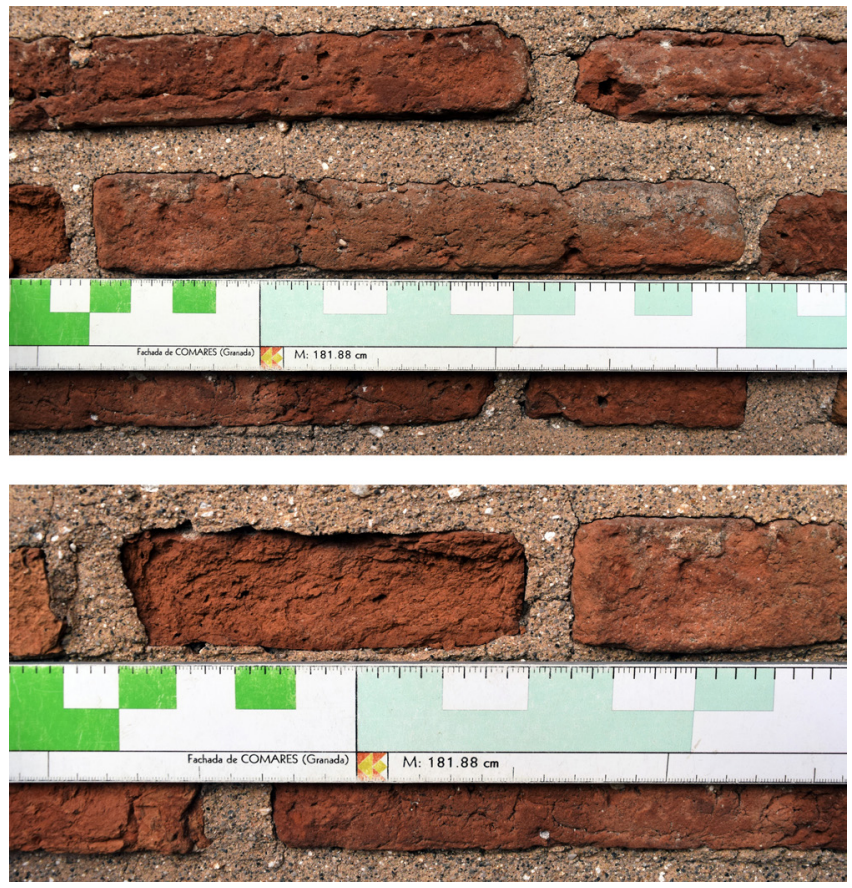

Figura 12. Formato tipo de las fábricas de ladrillo.

de $12 \cdot \sqrt{ } 2+14$ palmos de radio $(234.7 \mathrm{~cm})$. Se detecta un ligero desplome hacia el exterior de la parte superior del arco y cuerpo superior, de unos $2 \mathrm{~cm}$ en el centro.

El tamaño de la ventana bífora superior se ajusta a 1 braza cuadrada, y el diseño de sebqa de sus laterales se basa en rombos de $2 \cdot \sqrt{ } 2+1$ de ancho por $4 \cdot \sqrt{ } 2$ palmos de altura $(29 \times 42.9 \mathrm{~cm})$.

En los laterales interiores de la portada existen unos nichos de $2 \cdot \sqrt{ } 2+1$ codos de ancho, 1 codo de fondo y coro-

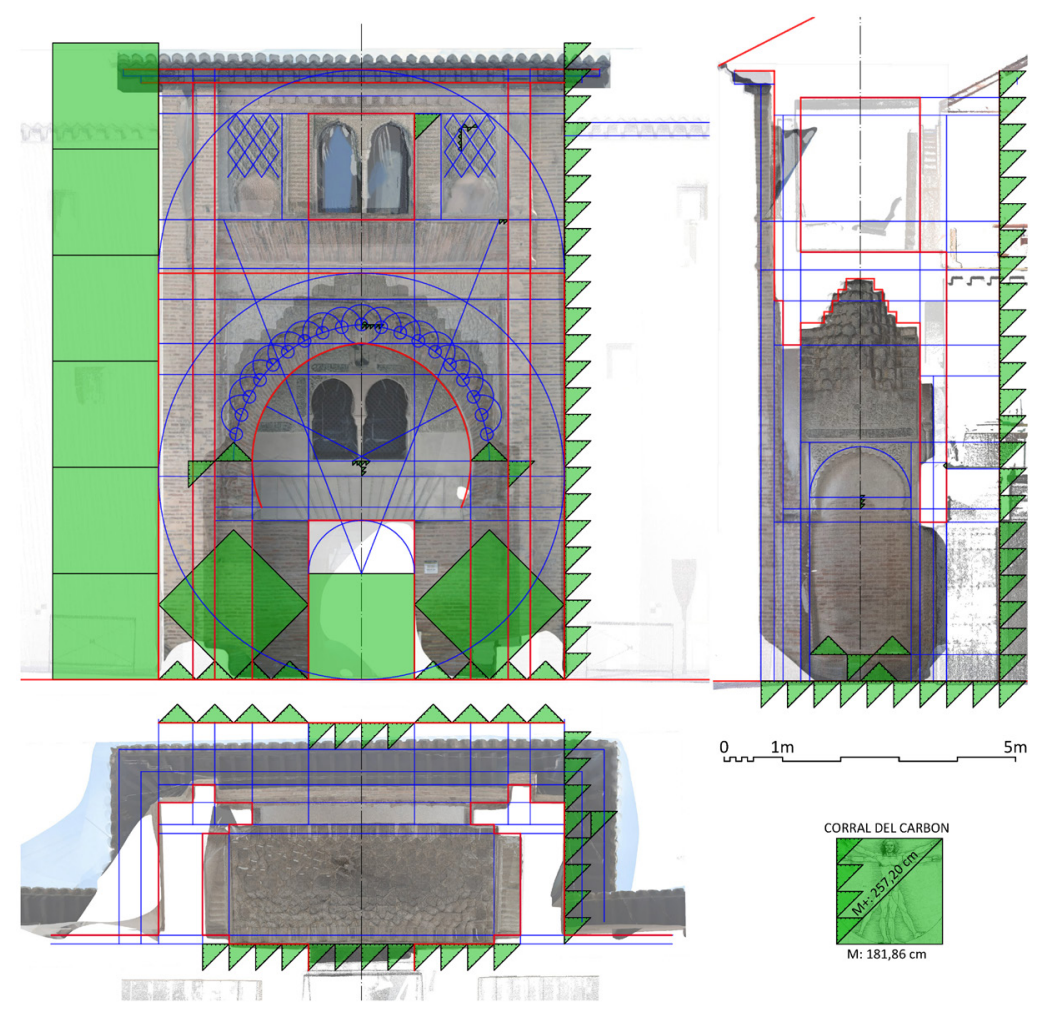

Figura 11. Antropometría de la portada. Alzado, planta cenital y sección. 
nados por arcos de herradura. No obstante la métrica de los ladrillos y piezas cerámicas de los bancos existentes aquí y en el vestíbulo interior coincide con la del Palacio de Carlos V.

La portada, así como algunas de las pilastras del patio, están construidas con fábrica de ladrillo de formato distinto al de la solería. En el caso general de la Figura 12 el largo es $2 \cdot \sqrt{ } 2+1$ palmos (casi 1 pie), el ancho $2 \cdot \sqrt{ } 2+4$ dedos y el grueso vuelven a ser 2 dedos $(29 \times 12.9 \times 3.8 \mathrm{~cm})$.

\subsection{El mocárabe}

El ámbito del techo de mocárabes en el vestíbulo de la portada del Corral del Carbón (Figura 13) se ajusta en planta a un rectángulo de $10 \times 4.5$ codos (4.55 x 2.05 m). El mocárabe presenta una altura regular de 10 dedos $(19 \mathrm{~cm})$ en cada uno de sus 12 niveles o pisos, hasta alcanzar la altura total de 5 codos $(2.27 \mathrm{~m})$ de altura.

Las ménsulas de arranque del mocárabe en sus lados largos disponen de 12 dedos de vuelo y de una separación racional. El eje de las ménsulas centrales distan 12 dedos al eje principal, y el resto 18 entre sí. En vertical también se escalonan regularmente por niveles, adoptando disposición alineada.

Como la naturaleza del sistema modular de mocárabes genera siempre composiciones dinámicas derivadas de la geometría del octógono (22), su dimensión total así como todas las parciales serán de naturaleza irracional. Sin embargo suelen ajustarse por necesidad a un ámbito definido racionalmente.

Aquí las adarajas (23) que se utilizaron fueron medios cuadrados o atacia de $\sqrt{ } 2+6$ dedos de lado $(14 \mathrm{~cm})$. Su diagonal, y el largo del rectángulo $\sqrt{ } 2$ o conza, es $6 \cdot \sqrt{ } 2+2(20 \mathrm{~cm})$, y su mitad $3 \cdot \sqrt{ } 2+1$ corresponde con la altura menor del triángulo cordobés o dumbaque.

La modulación total de la geometría del mocárabe se ajusta con precisión a las dimensiones racionales del ámbito. Así el largo total teórico de la composición alcanza $92 \cdot \sqrt{ } 2+110$ dedos, que son 10 codos (240 dedos) con un despreciable error del $+0.04 \%$.

Hay que destacar que la distribución racional de las ménsulas de arranque se corresponde también con vértices de la geometría irracional del mocárabe. Los 18 dedos $(34 \mathrm{~cm})$ de separación entre arranques se adaptan con la misma precisión al tamaño de una atacia más una conza del mocárabe $(7 \cdot \sqrt{ } 2+8$ dedos $)$.

Si bien el ajuste del mocárabe al largo total es prácticamente coincidente, en sentido perpendicular los desajustes son significativos, a pesar de ser el ancho bastante más corto. En principio la geometría teórica alcanza los $24 \cdot \sqrt{ } 2+42$ dedos de ancho, buena aproximación también a 76 dedos enteros $(1.44 \mathrm{~m})$. Como las ménsulas de arranque disponen de 12 dedos de vuelo cada una, entre éstas y el mocárabe existe teóricamente una franja de residuo de 4 dedos ( 1 palmo) a ambos lados para completar el ancho total del ámbito.

El detalle (Figura 14) muestra que en este sentido ciertas adarajas disponen de juntas de un dedo de ancho de manera que los desajustes son cada vez mayores desde el centro hasta los extremos, absorbiéndose finalmente buena parte del residuo teórico. Mediante estas medinas (24) discontinuas el ancho real del mocárabe $(1.59 \mathrm{~m})$ se amplía hasta 2 palmos sobre su valor teórico para adaptarse al ámbito a cubrir.
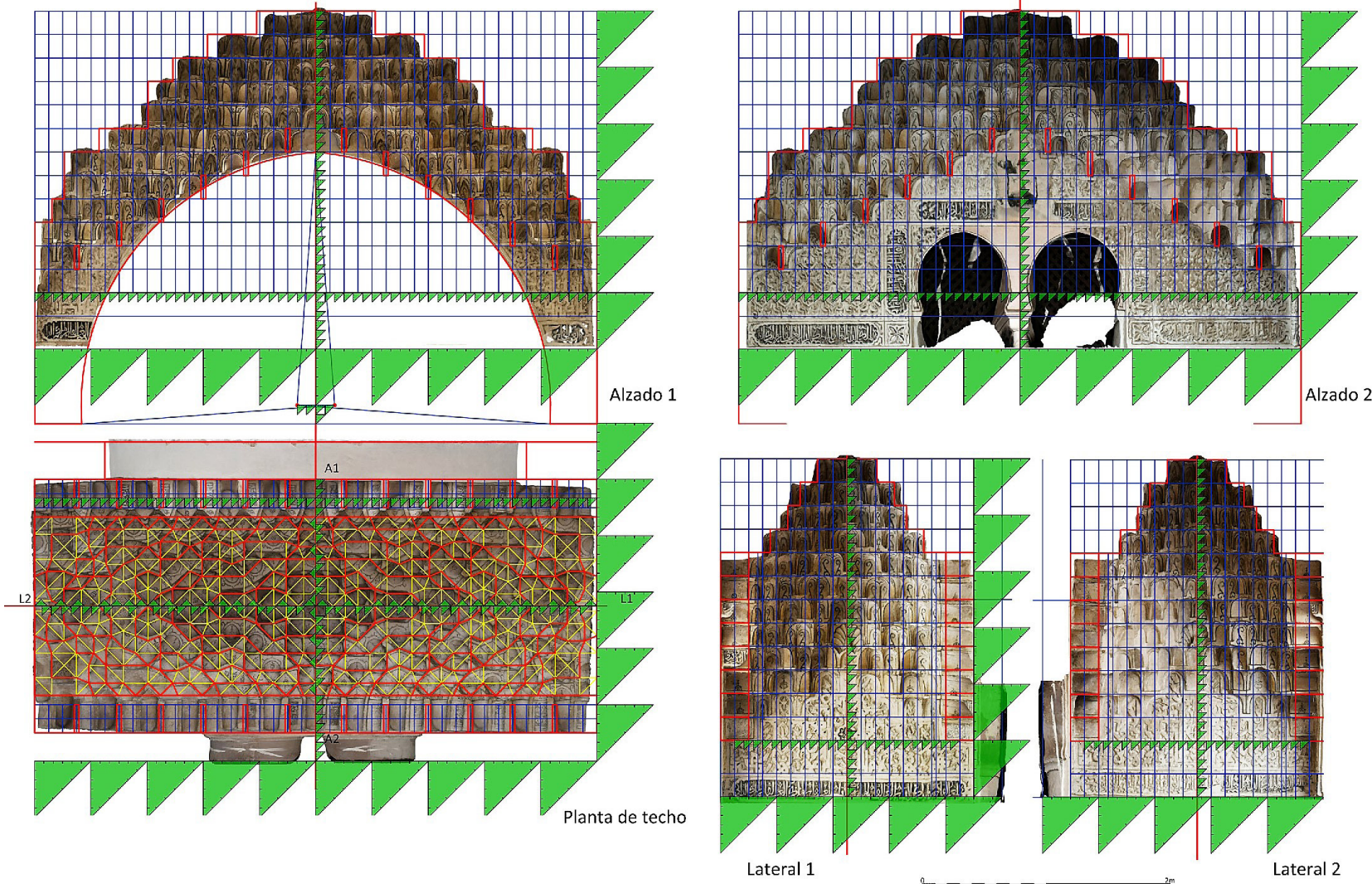

Figura 13. Antropometría del mocárabe. Planta cenital y alzados-sección. 


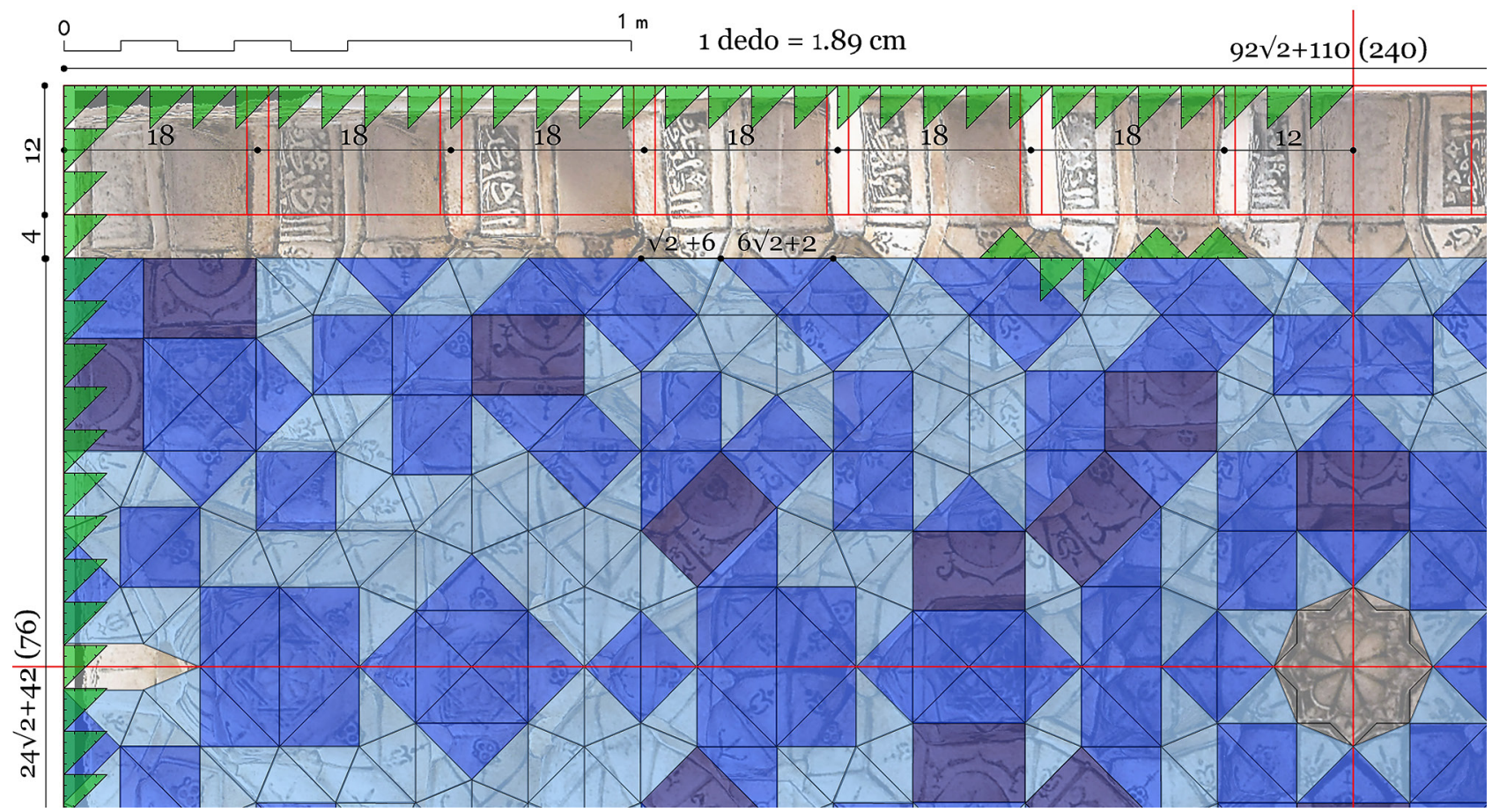

Figura 14. Antropometría del mocárabe. Detalle de un cuadrante

Además se observan algunas ligeras deformaciones en el perímetro de la planta, mayores espesores de revestimiento en la zona de los rincones, y cierta curvatura hacia el exterior del plano del arco de acceso ya apuntada. Escasas diferencias más presenta la forma teórica con la real del mocárabe, todas ellas achacables a patologías o intervenciones posteriores, y no a errores de diseño o construcción.

\subsection{Medida real y medida teórica}

Para la revisión y verificación final de estos resultados se ha realizado una serie de lecturas de la medida real de ciertos elementos representativos del edificio en planta baja. Estos valores se exponen en la Tabla 3 tras su medida teórica expresada en diagonales y lados de unidad antropométrica, y su equivalencia en centímetros.

Como se puede constatar, las desviaciones de la medida real respecto de la medida teórica se mantienen por lo general inferiores al 1\% fijado de tolerancia, siendo mínimas en las medidas generales.

Los mayores excesos se producen en el ancho de la galería, relacionados con la mencionada curvatura que presenta, siendo el resto de diferencias achacable a errores de replanteo, deformaciones, pérdidas o añadidos.

Tabla 3. Medidas teóricas y reales de verificación.

\begin{tabular}{|c|c|c|c|c|c|c|c|c|c|c|c|c|}
\hline \multirow[b]{2}{*}{ Denominación } & \multicolumn{6}{|c|}{ MEDIDA TEÓRICA } & \multicolumn{6}{|c|}{ MEDIDA REAL } \\
\hline & Diag. & Lados & $\mathrm{x}$-dec & AntroU & Fracción & $\mathbf{c m}$ & L1 & e1 & L2 & e2 & L3 & e3 \\
\hline Módulo M & & 1 & 1 & BRAZA & 1 & 181,86 & & & & & & \\
\hline Ancho galerías & & 1 & 1 & BRAZA & 1 & 181,86 & 189,3 & $3,93 \%$ & 176,3 & $-3,16 \%$ & 144,5 & $-25,86 \%$ \\
\hline Ancho libre patio & & 17 & 17 & VARA & $1 / 2$ & 1545,83 & 1549,8 & $0,26 \%$ & 1545,2 & $-0,04 \%$ & & \\
\hline Ancho patio c/galerías & & 11 & 11 & BRAZA & 1 & 2000,49 & 1992,8 & $-0,39 \%$ & 1950,9 & $-2,54 \%$ & 1992,24 & $-0,41 \%$ \\
\hline Fondo libre patio & 7 & 27 & 36,9 & CODO & $1 / 4$ & 1677,66 & 1730 & $3,03 \%$ & 1695,5 & $1,05 \%$ & 1673 & $-0,28 \%$ \\
\hline Fondo patio c/galerías & 7 & 37 & 46,9 & CODO & $1 / 4$ & 2132,32 & 2128,5 & $-0,18 \%$ & 2104,2 & $-1,34 \%$ & 2129,6 & $-0,13 \%$ \\
\hline Lado acerado fuente & & 2 & 2 & BRAZA & 1 & 363,73 & 371,6 & $2,12 \%$ & 361,4 & $-0,64 \%$ & & \\
\hline Cota nivel 3 & & 21 & 21 & CODO & $1 / 4$ & 954,78 & 968,6 & $1,43 \%$ & 966 & $1,16 \%$ & & \\
\hline Ancho portada & 2 & 1 & 3,83 & BRAZA & 1 & 696,25 & 689,5 & $-0,98 \%$ & & & & \\
\hline Ancho alfiz & 5 & 4 & 11,07 & CODO & $1 / 4$ & 503,35 & 504,2 & $0,17 \%$ & & & & \\
\hline Ancho arco & 3 & 4 & 8,24 & CODO & $1 / 4$ & 374,76 & 375,2 & $0,12 \%$ & & & & \\
\hline Ancho huecos & & 1 & 1 & BRAZA & 1 & 181,86 & 182,5 & $0,35 \%$ & 183,6 & $0,95 \%$ & 181,5 & $-0,20 \%$ \\
\hline Ancho vestíbulo & & 12 & 12 & CODO & $1 / 4$ & 545,59 & 541,8 & $-0,70 \%$ & & & & \\
\hline Alto total & & 23 & 23 & CODO & $1 / 4$ & 1045,71 & 1050,5 & $0,46 \%$ & & & & \\
\hline Fondo portada & & 5 & 5 & CODO & $1 / 4$ & 227,33 & 213,4 & $-6,53 \%$ & 209,7 & $-8,41 \%$ & & \\
\hline Ancho mocárabe & & 4,5 & 4,5 & CODO & $1 / 4$ & 204,6 & 204,5 & $-0,05 \%$ & 206,7 & $1,02 \%$ & & \\
\hline Largo mocárabe & & 10 & 10 & CODO & $1 / 4$ & 454,66 & 461,5 & $1,48 \%$ & 453,6 & $-0,23 \%$ & & \\
\hline
\end{tabular}




\section{CONCLUSIONES}

La superposición y ajuste de proyecciones láser 3D y fotogramétricas genera sugerentes y detalladas orto vistas que facilitan el registro de elementos vistos y ocultos, y por tanto aumentan la información en verdadera magnitud de la obra. Por ello, verificadas y dotadas de una referencia métrica, constituyen fiables y útiles fuentes documentales para el estudio geométrico general de la obra, y en particular para realizar el análisis antropométrico del que se obtienen los posibles parámetros originales de la composición arquitectónica.

A pesar de la inusual curvatura que presentan las galerías del patio del Corral del Carbón, son reconocibles y reconstruibles las trazas del edificio canónicamente moduladas por lados y diagonales de cuadrado de la métrica identificada como Nazarí 2. Especialmente en la representativa portada que sigue el esquema básico de las composiciones nobles, con un módulo recto centrado flanqueado por diagonales que componen su ancho exacto, y alturas racionales que producen distintas proporciones notables en el alzado.
Este principio compositivo mediante lados y diagonales explica y justifica cómo la rígida geometría irracional del mocárabe se controla mediante loables aproximaciones dinámicas a los valores racionales de su ámbito. También permite detectar partes ejecutadas con distinta métrica, y otras que coinciden con la métrica general aunque por su buen estado de conservación se suponen modernas.

Asumiendo que estos parámetros métricos podrían ser una inédita fuente de conocimiento directo de cada una de las obras, y datos fundamentales para cualquier otra interpretación geométrica, sería ahora necesario adaptar nuestro actual esquema mental de una arquitectura clásica basada en la razón pura por otro no mucho más complicado, pero sustancialmente distinto al considerar no sólo las proporciones aritméticas sino también las armónicas $\sqrt{ } \mathbf{2}$.

Por lo tanto la técnica actual permite un riguroso y preciso registro del patrimonio material, que puede y debería ser interpretado antropométricamente desde el primer momento. Especialmente útil puede resultar esta parametrización de dimensiones armónicas mediante lados y diagonales de cuadrado en el modelado 3D, y sencilla su implementación en las actuales herramientas eBIM.

\section{REFERENCIAS}

(1) Almagro, A. (2004). Levantamiento arquitectónico. Granada: Universidad de Granada. Recuperado de http://digital. csic.es/handle/10261/19802

(2) Monge, G. (1803). Geometría descriptiva, lecciones dadas en las escuelas normales en el año tercero de la República. Madrid: Imprenta Real. Recuperado de http://digibug.ugr.es/handle/10481/31418

(3) Kula, W. (1980). Las medidas y los hombres. Madrid: Siglo XXI.

(4) Rodríguez-Moreno, C., Reinoso-Gordo, J.F., Rivas-López, E., Gómez-Blanco, A., Ariza-López, F.J., y Ariza-López, I. (2018). From point cloud to BIM: An integrated workflow for documentation, research and modelling of architectural heritage. Survey Review, 50 (360): 212-231.

(5) Calatrava, J. (2014). Introducción. En Arredondo, D. et al. (Eds.), De la casa al territorio. Jornadas de investigación en arquitectura (pp. 7-12). Granada: Universidad de Granada.

(6) Evers, B. y Thoenes, C. (2015). Teoría de la arquitectura: Del Renacimiento a la actualidad. Biblioteca de Arte de los Museos Nacionales de Berlín.

(7) Wittkower, R. (1968). La arquitectura en la edad del Humanismo. Buenos Aires: Nueva Visión.

(8) Vitrubio, M. (2007). Los diez libros de arquitectura. Madrid: Akal.

(9) Moya, L. (1981). Relación de diversas hipótesis sobre las proporciones del Partenón. Academia: Boletín de la Real Academia de Bellas Artes de San Fernando, 52: 25-156.

(10) Roldán Medina, F.J. (2011). La Escuadra Sagrada. Madrid: Bubok Publishing S.L.

(11) Moya, L. (1993). La arquitectura cortés y otros escritos. Madrid: Colegio Oficial de Arquitectos de Madrid.

(12) Roldán Medina, F.J. (2014). Principios de metrología en la arquitectura del pasado. Granada: Universidad de Granada. Recuperado de http://hdl.handle.net/10481/31355.

(13) Roldán Medina, F.J. (2017). Nuevas herramientas métricas para el estudio del patrimonio arquitectónico. En M. Palma Crespo, M.L. Gutiérrez Carrillo y R. García Quesada (eds.), Reuso Granada 2017. Sobre una arquitectura hecha de tiempo, pp. 275-280. Granada: Universidad de Granada.

(14) Orihuela Uzal, A. (2004). La Alhóndiga Nueva o Corral del Carbón, en Granada. En Obras Singulares de la Arquitectura y la Ingeniería en España (pp. 90-92). Madrid: Grupo FCC.

(15) Reinoso-Gordo, J.F., Rodríguez-Moreno, C., Gómez-Blanco, A., y León-Robles, C. (2018). Cultural heritage conservation and sustainability based on surveying and modeling: The case of the 14th century building Corral del Carbón (Granada, Spain). Sustainability, 10(5): 1370. https://doi.org/10.3390/su10051370

(16) Roldán Medina, F.J. (2015). Análisis antropométrico de la mezquita-catedral de Córdoba. Informes de la Construcción, 67(539): eo93. https://doi.org/10.3989/ic.14.024.

(17) Roldán Medina, F.J. (2016). Estudios antropométricos del patrimonio. Finalista Convocatoria Investigación en Arquitectura y Urbanismo. XIII Bienal Española de Arquitectura y Urbanismo. http://doi.org/10.13140/RG.2.1.2589.9923

(18) Roldán Medina, F.J. (2018). Geometría y métrica en la planta circular del Palacio de Carlos V. En P.A. Galera Andreu y S. Frommel (coord.), El patio circular en la arquitectura del Renacimiento: de la Casa de Mantegna al Palacio de Carlos $V$, pp. 355-381. Sevilla: Universidad Internacional de Andalucía.

(19) Beacham, R., Niccolucci, F. y Denard, H. (2009). The London Charter. Londres: Hugh Denard, King's College London.

(20) Pennethorne, J. y Robinson, J. (1878). The Geometry and Optics of Ancient Architecture: Illustrated by Examples from Thebes, Athens and Rome. London: Williams and Norgate. 
(21) Torres Balbás, L. (1946). Las alhóndigas hispanomusulmanas y el Corral del Carbón de Granada. al-Andalus, 11: 446-480.

(22) Palacios Gonzalo, J.C. (2011). Las cúpulas de mocárabes. En Actas del Séptimo Congreso Nacional de Historia de la Construcción (pp.1021-1029). Madrid: Instituto Juan de Herrera.

(23) Nuere Matauco, Enrique (1990). La Carpintería de Lazo. Lectura dibujada del manuscrito de fray Andrés de San Miguel. Málaga: Colegio de arquitectos.

(24) Piñuela García, M. (2017). Sobre la traza de los mocárabes: adarajas, medinas y la pieza «grullillo» de López de Arenas. En Actas del Décimo Congreso Nacional y Segundo Congreso Internacional Hispanoamericano de Historia de la Construcción (pp. 1267-1277). Madrid: Instituto Juan de Herrera. 